\title{
Preparation and Characterization of Axial Gradient Silicon Carbide Fibers with Sinusoidal Electrical Resistivity
}

\author{
Tianjiao Hu, Xiaodong Li, Wenjing Pu, Zhenyu Xia \\ College of Science, National University of Defense Technology, Changsha, China \\ Email: tjhu617@gmail.com
}

How to cite this paper: $\mathrm{Hu}, \mathrm{T} . J ., \mathrm{Li}, \mathrm{X} . \mathrm{D}$., $\mathrm{Pu}$, W.J. and Xia, Z.Y. (2016) Preparation and Characterization of Axial Gradient Silicon Carbide Fibers with Sinusoidal Electrical Resistivity. Journal of Materials Science and Chemical Engineering, 4, 58-64. https://doi.org/10.4236/msce.2016.412007

Received: September 20, 2016 Accepted: December 6, 2016

Published: December 9, 2016

\begin{abstract}
Two types of silicon carbide fibers with sinusoidal electrical resistivity were prepared by using different pyrolysis technology. The relationship between the microstructure and the electrical resistivity of these fibers was investigated and compared. The results indicated that carbon layer was the main conductive phase in the SiC fibers obtained by means of one step pyrolysis, whereas a free carbon phase governed the conductivity of the $\mathrm{SiC}$ fibers prepared through two step pyrolysis mode.
\end{abstract}

\section{Keywords}

Silicon Carbide, Fiber, Electrical Property, Sinusoidal

\section{Introduction}

The silicon carbide ( $\mathrm{SiC}$ ) fibers are typically used as reinforcement for high temperature structural ceramic composites due to their excellent tensile strength, stiffness and high temperature resistivity in oxidizing atmosphere. Besides the prominent mechanical properties, the $\mathrm{SiC}$ fibers also exhibit attractive electrical properties. The $\mathrm{SiC}$ fibers are n-type semiconductors with a controllable electrical resistivity $(\rho)$ between $10^{-2}-10^{6}$ $\Omega \cdot \mathrm{cm}$ [1]. The specific resistivity of the fiber can be adjusted via heat treatment [2], surface modification [3] or heteroatom doping [4] [5], et al. For example, the Nippon Carbon company produced a commercial type of $\mathrm{SiC}$ fibers (trade name: Nicalon NL-607) coated with a carbon layer. This fiber shows different $\rho$ in the range of $10^{-1}$ $10^{3} \Omega \cdot \mathrm{cm}$ according to different carbon layer thickness [3]. The tunable electrical conductivity together with the excellent high-temperature thermal and mechanical properties makes the $\mathrm{SiC}$ fibers powerful candidate materials for functional applications [6] [7] [8]. 
Functional gradient materials (FGM) are composite materials contain gradients in morphology or in composition. Such gradients bring the FGMs a number of advantages that make them attractive in potential applications. For the SiC fibers fabrication, a $\mathrm{ZrO}_{2} / \mathrm{SiC}$ fiber with radial gradient composition was prepared by the Ishikawa's group [9]. This gradient fiber exhibits excellent strength and alkali resistance owing to its gradient surface layer. Actually, owing to the unique features of the fabrication process, the polymer-derived $\mathrm{SiC}$ fibers are more or less innate gradient along the radial direction (so-called core-shell structure). But, as a real FGM, the continuous SiC fibers with gradient structure and properties in the axial direction have never been reported.

In this paper, we prepared a $\mathrm{SiC}$ fiber with a periodically varying electrical resistivity in the axial direction. The structure alternation of the $\mathrm{SiC}$ fiber along the axial direction was investigated by X-ray diffraction (XRD), transmission electron microscopy (TEM) and auger electron spectroscopy (AES). Base on these analyses, the relationship between the structure and the electrical properties of the graded fibers are discussed.

\section{Experiments}

The pyrolysis apparatus of gradient $\mathrm{SiC}$ fibers was illustrated in Figure 1. A rotating spool having the shape of an ellipse was employed in this system to periodically adjust the rolling speed during the pyrolysis process. The cyclic rolling speed led to a periodic variation of the pyrolysis time and subsequently resulted in a periodic varied structure of the as-received fibers. All of the pyrolysis experiments in this study were conducted at $1300^{\circ} \mathrm{C}$ and the temperature was measured by a thermocouple sited in the middle of the furnace.

The oxygen-cured polycarbosilane (PCS) fibers, provided by the National University of Defense Technology [10], were adopted as starting materials for the preparation of gradient $\mathrm{SiC}$ fibers. They have a molar composition of $\mathrm{SiC}_{1.54} \mathrm{O}_{1.035} \mathrm{H}_{2.78}$ and a mean diameter of $15 \mu \mathrm{m}$ with 600 filaments in a bundle. In the experiments, the cured PCS fibers were pyrolyzed under two different pyrolysis modes. In the first pyrolysis mode, namely the one step pyrolysis mode, the cured PCS fibers were directly converted into $\mathrm{SiC}$ fibers via drawing through the corundum tube of the pyrolysis furnace by the elliptic rotating spool. In the second pyrolysis mode, denoted as the two step pyrolysis mode, the cured PCS fibers were firstly heat treated at $800^{\circ} \mathrm{C}$ for 10 minutes to obtain pre-pyrolysis fibers and then the pre-pyrolysis fibers were converted into $\mathrm{SiC}$ fibers by drawing through the corundum tube in the same way as in the one step pyrolysis
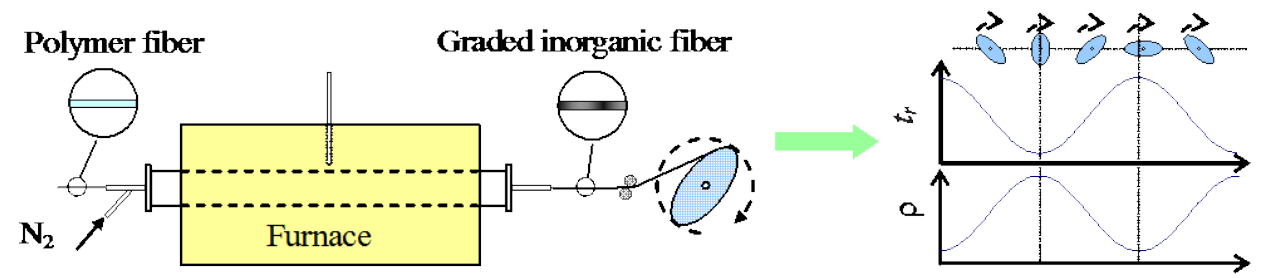

Figure 1. Schematic diagram of a general process for preparation of graded ceramic fiber in the axial direction. 
mode. The as-received fibers derived from the one step and two step pyrolysis modes, were labeled as I-SiC and II-SiC, respectively.

\section{Characterization of the SiC Fibers}

For the structure and properties investigation, the as-received fibers were cut into small segments with a length of $25 \mathrm{~mm}$. The following measurements were applied to each single segment.

The morphology of the gradient $\mathrm{SiC}$ fibers was observed by using a scanning electron microscope (SEM, S-4800, Hitachi). The crystal phases of the fibers were identified with an X-ray diffractometer (Rigaku Co., Type Max2550, Tokyo, Japan) using Cu Ka radiation, and the apparent size of $\beta$-SiC crystallite was calculated from the half value width of (111) peak using Scherrer's formula. Auger electron spectroscopy (AES, PHI-700, ULVAC-PHI) characterization was performed with a scanning $40 \mathrm{~nm}$ microprobe equipped with an Ar+ sputtering gun. The variations of the intensities of the Auger electron peaks as a function of the sputtering depth were used to draw semi-quantitative composition-depth profiles from the sample surface.

The resistance $(\mathrm{R})$ of the fiber segments was directly measured by an ultra high resistance meter (Model-TH2683, Tonghui) using single filament of length (L) $10 \mathrm{~mm}$ at ambient temperature. The specific resistivity $(\rho)$ was calculated from the resistance according to the equation: $\rho=\pi \mathrm{d}^{2} \mathrm{R} / 4 \mathrm{~L}$. Diameter ( $d$ ) of fiber was determined using optical microscopy. The tensile strength $(\sigma)$ of the fibers was measured using a tensile testing machine (YG-001, Taicang) with a gauge length of $10 \mathrm{~mm}$ and a crosshead speed of $2 \mathrm{~mm} / \mathrm{min}$ at room temperature. Every data point of $\rho$ and $\sigma$ is the average value of 20 monofilaments.

\section{Results and Discussions}

Figure 2(a) shows the elliptic rotating spool and the as-received gradient SiC fibers collected by this spool. The fibers obtained in this experiment were black colored and of flexible form. As can be observed from the SEM images (Figure 2(b) and Figure 2(c)), both the I-SiC and II-SiC exhibit smooth surface and have average diameter of $12 \mu \mathrm{m}$.

Figure 2(a) shows the elliptic rotating spool and the as-received gradient SiC fibers collected by this spool. The fibers obtained in this experiment were black colored and of flexible form. As can be observed from the SEM images (Figure 2(b) and Figure 2(c)), both the I-SiC and II-SiC exhibit smooth surface and have average diameter of $12 \mu \mathrm{m}$.

Figure 3 shows the retention time $\left(t_{r}\right)$ generated by the elliptic rotating spool and related specific resistivity $(\rho)$ of the $\mathrm{SiC}$ segments. As the $t_{r}$ periodically changes from 4 to $40 \mathrm{~s}$, the I-SiC and II-SiC shows remarkable sinuate periodic $\rho$ along the axial direction and the fluctuating period of the $\rho$ is in well accordance with that of the $t_{r}$ However, despite the same pyrolysis temperature and similar amorphous structure indicated by the XRD patterns (shown in Figure 4), the I-SiC and II-SiC exhibit different $\rho$ in the range of $10^{0}-10^{2} \Omega \cdot \mathrm{cm}$ and $10^{3}-10^{5} \Omega \cdot \mathrm{cm}$, respectively.

As presented in studies concerning the electrical conductive mechanism of polymer 

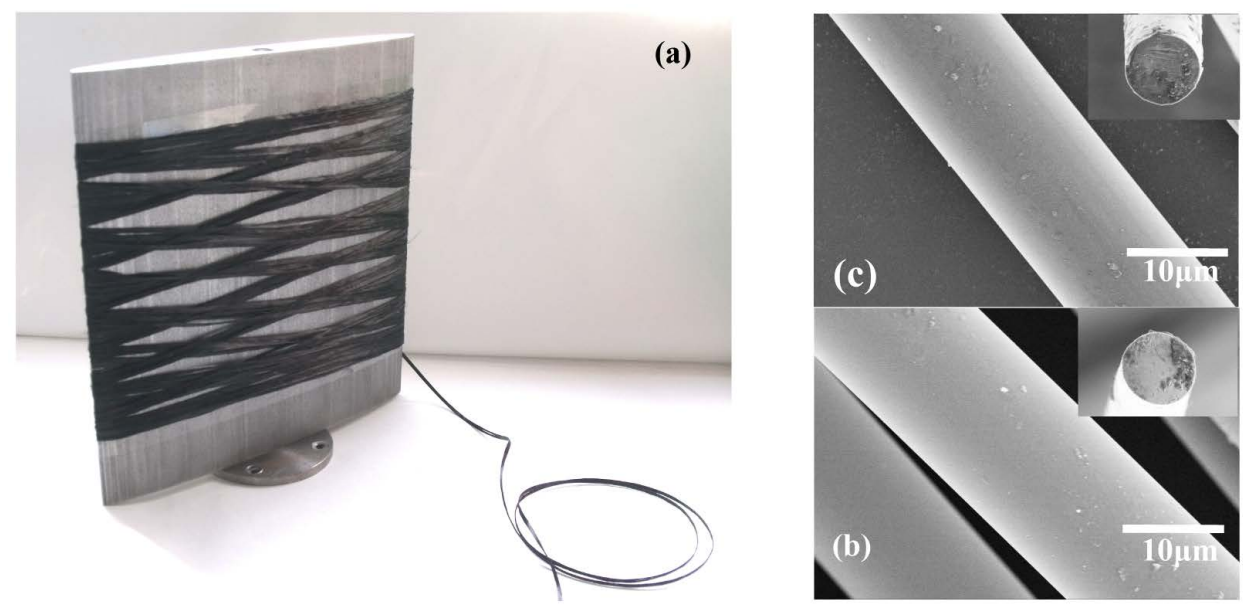

Figure 2. Axial gradient $\mathrm{SiC}$ fibers with sinuate periodic electrical resistivity; (a) The elliptic rotating spool and the as-received gradient $\mathrm{SiC}$ fibers collected by this spool; (b) surface and cross-section (inset) of the I-SiC; (c) surface and cross-section (inset) of the II-SiC.

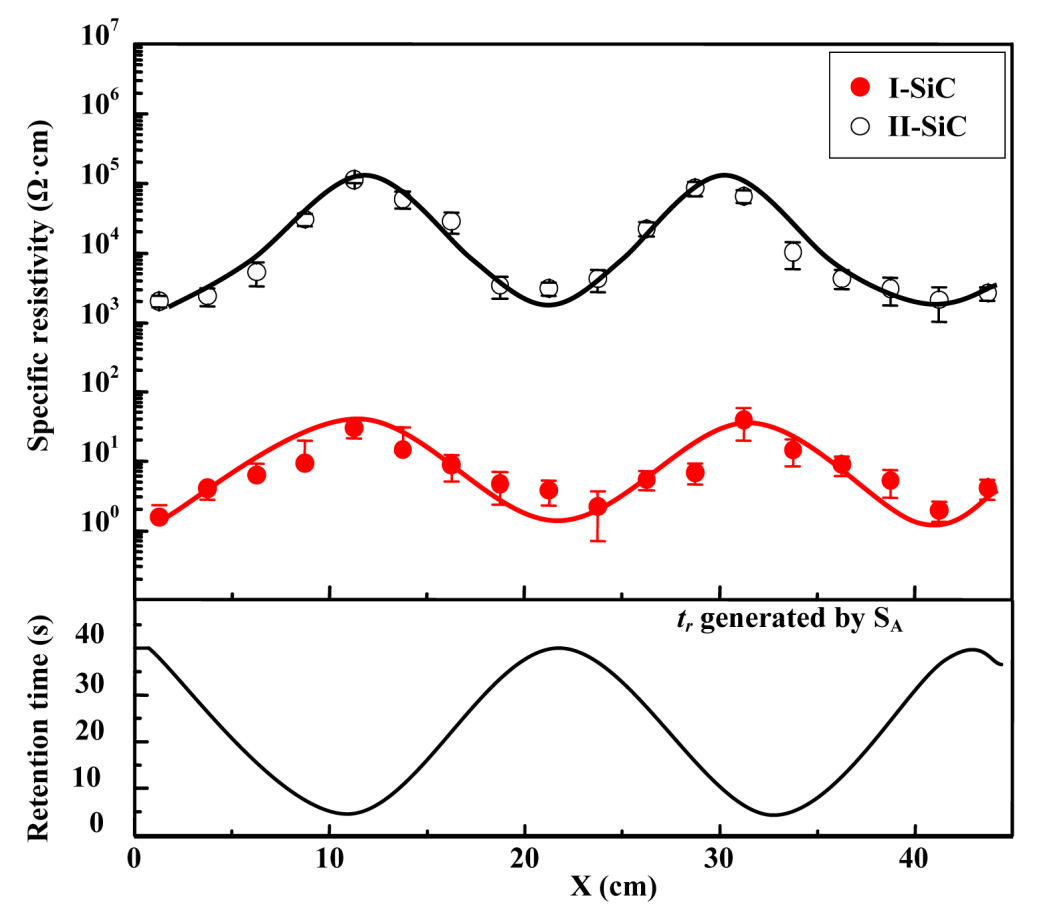

Figure 3. The rolling speed generated by the elliptic rolling spool and related specific resistivity of the I-SiC and II-SiC fiber segments. $\mathrm{X}$ is a system that denotes the actual distance of test point to the origin along axial direction. The origin is settled at the point with the lowest test value of $\rho$ in one period.

derived $\mathrm{SiC}$ fibers, the amount of free carbon but mainly, its texture, governs the electrical properties of the fibers according to a percolation effect [11]. Therefore, the investigation of the structure evolution in these gradient $\mathrm{SiC}$ fibers is focus on the carbon texture in the following studies. Table 1 list the fiber segments which were selected as the testing samples for the structure investigation. 


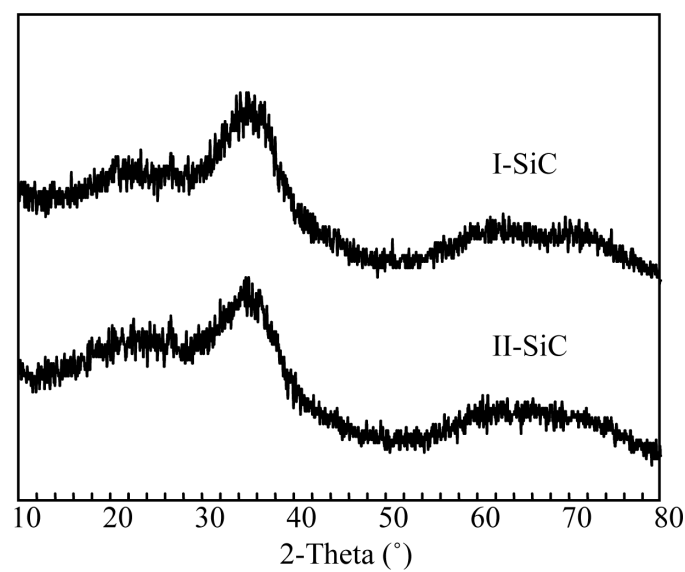

Figure 4. XRD patterns of the I-SiC and II-SiC with $\rho$ in the range of $10^{0}-10^{2} \Omega \cdot \mathrm{cm}$ and $10^{3}-10^{5}$ $\Omega \cdot \mathrm{cm}$, respectively.

Table 1. Testing samples for the structure investigation.

\begin{tabular}{cl}
\hline Samples & $\rho(\Omega \cdot \mathrm{cm})$ \\
\hline HR-I-SiC & $4.43 \times 10^{2}$ \\
LR-I-SiC & $1.16 \times 10^{0}$ \\
HR-II-SiC & $0.91 \times 10^{5}$ \\
LR-II-SiC & $1.50 \times 10^{3}$ \\
\hline
\end{tabular}

The AES analysis shows that a thin carbon layer appears for I-SiC fibers and the thickness of this carbon layer increases as the $\rho$ of corresponding fibers decreases (Figure 5(a) and Figure 5(b)). That is about $25 \mathrm{~nm}$ for the LR-I-SiC with $\rho$ of $1.16 \times 10^{0}$ $\Omega \cdot \mathrm{cm}$ and less than $5 \mathrm{~nm}$ for HR-I-SiC with $\rho$ of $4.43 \times 10^{2} \Omega \cdot \mathrm{cm}$. Considering the poor electrical conductivity of the amorphous structures, the different electric performance between the LR-I-SiC and HR-I-SiC segments suggests that the thickness of carbon layer controls the electric behavior of I-SiC fibers.

Apropos of the II-SiC fibers pyrolysis under the two step pyrolysis mode, a slightly oxidized surface layer is observed (Figure 5(c) and Figure 5(d)). The $\rho$ of II-SiC fiber is higher than that of I-SiC due to the absence of the carbon-enriched layer. This also indicated that the different electric performance between the LR-II-SiC and HR-II-SiC should be arose by the different inner structure.

\section{Conclusion}

A novel $\mathrm{SiC}$ fiber with a periodically varying electrical specific resistivity in the range of $10^{0}-10^{5} \Omega \cdot \mathrm{cm}$ along the axial direction was prepared by periodically changing the rolling speed during the pyrolysis process. Base on the structure analyses, the difference of the carbon layer thickness on the I-SiC fiber surface was responsible for the electrical specific resistivity variation, whereas a free carbon phase governed the conductivity of the II-SiC fibers. It is believed that the continuous $\mathrm{SiC}$ fibers with periodically varying electrical specific resistivity would find applications as the reinforcement for the functional materials. 


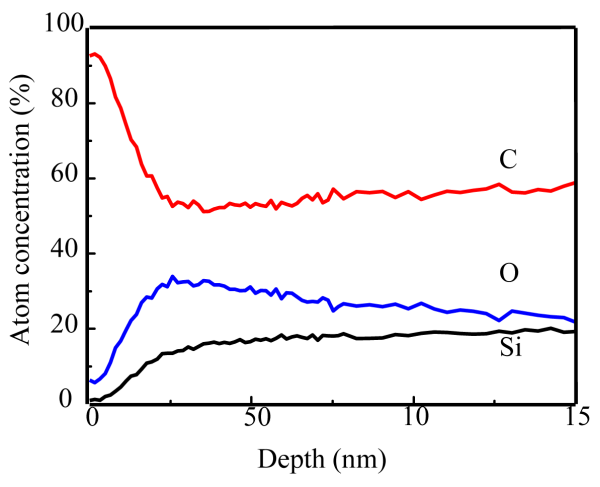

(a)

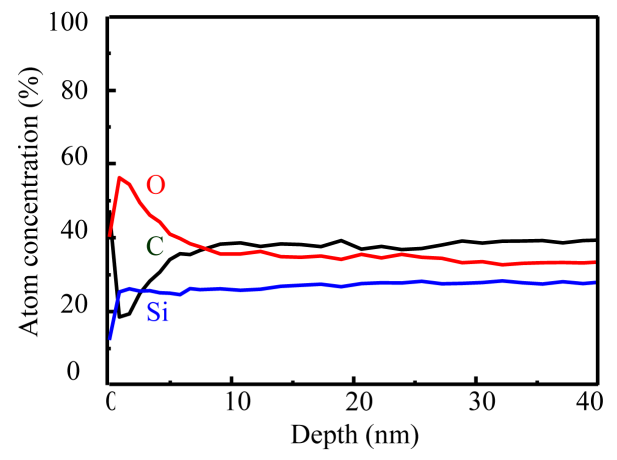

(c)

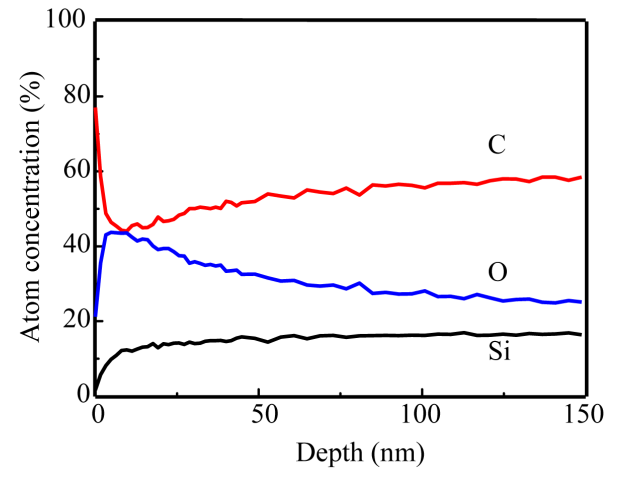

(b)

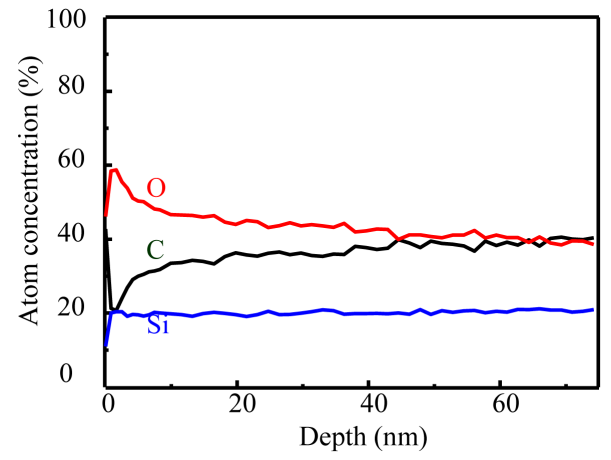

(d)

Figure 5. The AES analysis (depth-profiling mode) of the as-received SiC fiber segments: (a) LR-I-SiC; (b) HR-I-SiC; (c) LR-II-SiC; (d) HR-II-SiC.

\section{Acknowledgements}

This work was financially supported by the Chinese Natural Science Foundation (Grant No. 51402360) and Advanced Research Project of National University of Defense Technology (Grant No. JC14-02-06).

\section{References}

[1] Muto, N. (1990) Infrared Detection by Si-Ti-C-O Fibers. Journal of Amrican Ceramic Society, 73, 443. https://doi.org/10.1111/j.1151-2916.1990.tb06533.x

[2] Narisawa, M., Okamura, K. and Itoi, Y. (1995) Electrical Resistivity of Si-Ti-C-O Fibres after Rapid Heat Treatment. Journal of Material Science, 30, 3401-3406. https://doi.org/10.1007/BF00349886

[3] Ishikawa, T. (1994) Recent Developments of the SiC fiber Nicalon and Its Composites, Including Properties of the SiC fiber Hi-Nicalon for Ultra-High Temperature. Composite Science and Technology, 51, 135-144.

[4] Yamamura, T., Ishikawa, T., Shibuya, M., Hisayuki, T. and Okamura, K. (1988) Development of a New Continuous Si-Ti-C-O Fibre Using an Organometallic Polymer Precursor. Journal of Material Science, 23, 2589-2594. https://doi.org/10.1007/BF01111919

[5] Kagawa, Y., Matsumura, K., Iba, H. and Imahashi, Y. (2007) Potential of Short Si-Ti-C-O Fiber-Reinforced Epoxy Matrix Composite as Electromagnetic Wave Absorbing Material. Journal of Material Science, 42, 1116-1121. https://doi.org/10.1007/s10853-006-1437-1 
[6] Yamamura, T., Ishikawa, T. and Shibuya, M. (1992) Electromagnetic Wave Absorbing Material, USA, Patent, 5094907.

[7] Tan, E., Kagawa, Y. and Dericioglu, A.F. (2009) Electromagnetic Wave Absorption Potential of SiC-Based Ceramic Woven Fabrics in the GHz Range. Journal of Material Science, 44, 1172-1179. https://doi.org/10.1007/s10853-009-3257-6

[8] Ishikawa, T., Ichikawa, H., Imai, Y., Hayase, T. and Nagata, Y. (1985) Electromagnetic Wave Absorbers of Silicon Carbide Fibers, USA, Patent, 4507354.

[9] Ishikawa, T., Yamaoka, H., Harada, Y., Fujii, T. and Nagasawa, T. (2002) A General Process for in Situ Formation of Functional Surface Layers on Ceramics. Nature, 416, 64-67. https://doi.org/10.1038/416064a

[10] Yajima, S., Okamura, K., Josaburo, H. and Mamoru, O. (1976) Synthesis of Continuous SiC Fibers with High Tensile Strength. Journal of Amrican Ceramic Society, 59, 324-427. https://doi.org/10.1111/j.1151-2916.1976.tb10975.x

[11] Bouillon, E., Mocaer, D., Villeneuve, J.F., Pailler, R., Naslain, R., Monthioux, M., Oberlin, A., Guimon, C. and Pfister, G. (1991) Composition-Microstructure-Property Relationships in Ceramic Monofilaments Resulting from the Pyrolysis of a Polycarbosilane Precursor at 800 to $1400^{\circ} \mathrm{C}$. Journal of Material Science, 26, 1517-1530.

https://doi.org/10.1007/BF00544661

Submit or recommend next manuscript to SCIRP and we will provide best service for you:

Accepting pre-submission inquiries through Email, Facebook, LinkedIn, Twitter, etc.

A wide selection of journals (inclusive of 9 subjects, more than 200 journals)

Providing 24-hour high-quality service

User-friendly online submission system

Fair and swift peer-review system

Efficient typesetting and proofreading procedure

Display of the result of downloads and visits, as well as the number of cited articles

Maximum dissemination of your research work

Submit your manuscript at: http://papersubmission.scirp.org/

Or contact msce@scirp.org 